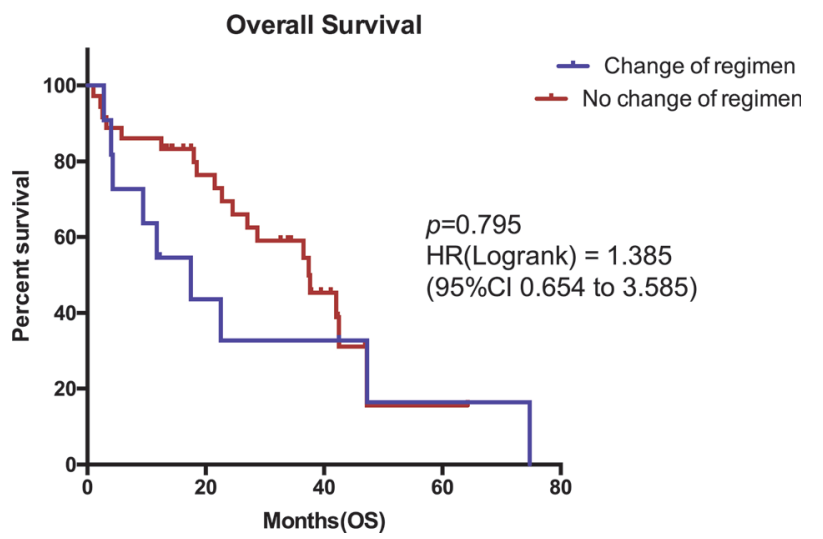

Abstract 124 Figure 1 Change in NACT regimen and impact on overall survival

six cycles. 39\% (24/61) of patients inoperable after 3 cycles changed chemotherapy regimens; 42\% (10/24) of the latter switched to weekly paclitaxel, $21 \%(5 / 24)$ to bevacizumabbased regimen, and $13 \%(3 / 24)$ to carboplatin + liposomal doxorubcin $\left(\right.$ Caelyx $\left.{ }^{\circledR}\right)$. 25\% (6/24) had palliative aromatase inhibitors or stopped chemo entirely. Of those who had their chemotherapy changed, only 1 patient in bevacizumab group (4\%) achieved optimal debulking. Median overall suvival(OS) in those who switched regimen was 17.47 vs 37.40 months in those who did not, $p=0.79$.

Conclusion* Switching chemotherapy regimen in previously inoperable patients did not lead to improved OS. This may reflect the poor prognosis conferred by inadequate response to platinum-based therapy, and needs further evaluation. Though the numbers in each group were small, a change to bevacizumab-based regimen did not appear to improve outcomes. The ICON $8 \mathrm{~b}$ study will provide further information regarding bevacizumab's role in the neoadjuvant setting.

\section{EXTRAPERITONEAL LEFT PELVIC LYMPHADENECTOMY}

A Rychlik*, J Rzepka, M Bidzinski. Maria Sklodowska-Curie National Research Institut of Oncology, Gynecologic Oncology, Warsaw, Poland

\subsection{6/ijgc-2021-ESGO.344}

Introduction/Background* Retroperitoneal lymphadenectomy of the pelvis is rarely performed due to its apparently high degree of difficulty. More and more clinical situations, especially in young people or those with medical problems, require breaking the treatment down into several steps.

Methodology The featured video describes the pelvic right retroperitoneal lymphadenectomy procedure.

Result(s)* As a result we present step by step procedure.

Conclusion* Retroperitoneal lymphadenectomy of the pelvis is a skill that should be mastered by everyone involved in endoscopic surgery in gynecological oncology.

\section{A COMPLICATED CASE OF PARAAORTIC NODAL DISSECTION IN A WOMAN WITH FALLOPIAN TUBE CANCER}

CR lavazzo*, A Fotiou, K Kokkali, S Lekka, D Giannoulopoulos, P Giannakas, G Vorgias. Metaxa Cancer Hospital of Piraeus, Gynecologic Oncology Department, Piraeus, Greece

10.1136/ijgc-2021-ESGO.345
Introduction/Background* Paraaortic lymph node dissection is a challenging surgical procedure. Recent data mentioned that bulky nodal disease in ovarian/fallopian tube cancer patients stage IIB and above should be dissected in fallopian tube cancer patients that optimal primary cytoreduction has been achieved. Methodology A challenging paraaortic lymph node dissection of a nodal block arising from fallopian tube cancer in a 76 years old patient is presented in this surgical video. Patient has been diagnosed with ovarian/fallopian tube cancer. Her CA 125 was $2161 \mathrm{IU} / \mathrm{ml}$ and her preoperative imaging has revealed a mass of right adnexa $7 \times 3 \mathrm{~cm}$, a metastatic abdominal mass involving the transverse colon and paraaortic lymph node $6 \mathrm{~cm}$ in dimension.

Result(s)* Abdominal hysterectomy, omentectomy, resection of the transverse colon, peritonectomies and dissection of the paraaortic nodal mass took place. No macroscopic residual disease was observed at the end of the procedure.

Conclusion* Removal of bulky nodal disease is indicated for patients with advanced ovarian/fallopian tube cancer. As applies in any paraaortic/retroperitoneal lymph node dissection resection of bulky lymph nodes can lead in intra or postoperative complications. Therefore, awareness of anatomical landmarks and anatomic variation are of paramount importance.

\section{SAFETY AND QUALITY OF LIFE OF FIRST-LINE MAINTENANCE OLAPARIB PLUS BEVACIZUMAB IN OLDER PATIENTS WITH ADVANCED OVARIAN CANCER IN THE PAOLA-1 TRIAL}

${ }^{1} \mathrm{C}$ Montégut ${ }^{*},{ }^{2} \mathrm{C}$ Falandry, ${ }^{3} \mathrm{~S}$ Cinieri, ${ }^{4} \mathrm{~L}$ Montane, ${ }^{1} \mathrm{~F}$ Rousseau, ${ }^{5} \mathrm{~F}$ Joly, ${ }^{6} \mathrm{~J}$ Frindte, ${ }^{7} \mathrm{AM}$ Mosconi, ${ }^{8} \mathrm{E}$ Guerra-Alia, ${ }^{9} \mathrm{C}$ Schauer, ${ }^{10} \mathrm{H}$ Fujiwara, ${ }^{11} \mathrm{IB}$ Vergote, ${ }^{12} \mathrm{G}$ Parma, ${ }^{13} \mathrm{G}$ Lindahl, ${ }^{4} \mathrm{~A}$ Anota, ${ }^{14} \mathrm{U}$ Canzler, ${ }^{15} \mathrm{~F}$ Marmé, ${ }^{16} \mathrm{E}$ Pujade-Lauraine, ${ }^{4,17}$ I Ray-Coquard, ${ }^{1} \mathrm{R}$ Sabatier. ${ }^{1}$ Institut Paoli-Calmette, and GINECO, Marseille, France; ${ }^{2} \mathrm{CHU}$ Lyon, and GINECO, Lyon, France; ${ }^{3}$ U.O.C. Oncologia Medica - Ospedale Senatore Antonio Perrino, and MITO, Puglia, Italy; ${ }^{4}$ Centre Léon Bérard, Lyon, France; ${ }^{5}$ Centre François Baclesse, and GINECO, Caen, France; ${ }^{6}$ Kliniken Essen-Mitte, Department of Gynecology and Gynecologic Oncology, and AGO, Essen, Germany; ${ }^{7}$ S.C. di Oncologia Medica Ospedaliera S. Maria della Misericordia - AO di Perugia, and MITO, Perugia, Italy; ${ }^{8}$ Hospital Ramon y Cajal, and GEICO, Madrid, Spain; ${ }^{9}$ Hospital Barmherzige Brüder Graz, and AGO, Graz, Austria; ${ }^{10}$ Jichi Medical University, and GOTIC, Tochigi, Japan; ${ }^{11}$ University Hospital Leuven, Leuven Cancer Institute, and BGOG, Leuven, Belgium; ${ }^{12}$ European Institute of Oncology IRCCS, and MANGO, Milan, Italy; ${ }^{13}$ Linköping University Hospital, and NSGO, Linköping, Sweden; ${ }^{14}$ Universitätsklinikum Carl Gustav Carus, Technische Universität Dresden, and AGO, Dresden, Germany; ${ }^{15}$ Universitätsklinikum Heidelberg, and AGO, Heidelberg, Germany; ${ }^{16}$ ARCAGY Research, and GINECO, Paris, France; ${ }^{17}$ University Claude Bernard Lyon I, and GINECO, Lyon, France

\subsection{6/ijgc-2021-ESGO.346}

Introduction/Background* The Phase III PAOLA-1/ENGOTov25 study (NCT02477644) demonstrated that the addition of olaparib to bevacizumab maintenance following standard platinum-based therapy plus bevacizumab improved progression-free survival (PFS) in patients with newly diagnosed advanced ovarian cancer (Ray-Coquard et al. NEJM 2019). We aimed to describe safety, quality of life (QoL), and efficacy with olaparib plus bevacizumab in patients $\geq 70$ years old.

Methodology Safety (adverse events [AEs] graded according to CTCAE v5.0) and QoL (measured using EORTC QLQ-C30 global health status [GHS]) data were collected. We compared safety by age (older $[\geq 70$ years] and younger patients $[<70$ years]) in the olaparib arm. Geriatric features, including Geriatric Vulnerability Score (GVS; Falandry et al. Ann Oncol 2013) items, and QoL by treatment arm were assessed in older patients. 